\title{
A importância política do Rio de Janeiro e de Buenos Aires a partir de 1808, no processo de independência do Brasil e da Argentina: questões gerais
}

The political importance of Rio de Janeiro and Buenos Aires since 1808, in the process

of independence from Brazil and Argentina: general issues

Hilton Meliande de Oliveira

Doutor em História - UERJ

Prof. CAP-UERJ

meliandehilton@gmail.com

\begin{abstract}
Resumo: O presente artigo é uma reflexão de parte da minha tese de doutorado e pretende abordar, de forma sucinta, a importância da província do Rio de Janeiro e do Cabildo de Buenos Aires para o processo de emancipação política do Brasil e Argentina, a partir do ano de 1808, fundamental para as transformações políticas na Iberoamérica. Nesse estudo, buscou-se traçar proximidades comparativas que destaquem como as referidas sociedades optaram e levaram a diferentes concepções políticas para seus processos de independência, monarquia e república, mas que ao fim, legitimaram a manutenção de suas respectivas elites sócio-políticas previamente existentes. $\mathrm{O}$ uso das fontes para o caso de Buenos Aires foi estabelecido a partir de trabalhos biográficos e manuais, sua discussão, interpretação e análise se segue a partir da reflexão e estudo sobre o tema em consonância a suas perspectivas iniciais.
\end{abstract}

Palavras Chaves: Rio de Janeiro, Buenos Aires, 1808.

\begin{abstract}
This article is a reflection of part of the doctoral thesis and intends to briefly address the importance that the province of Rio de Janeiro and the Cabildo of Buenos Aires had for the political emancipation process of Brazil and Argentina, from 1808 onwards, fundamental for political transformations in iberoamerica. In this study, we sought to draw comparative proximity that highlights how these societies chose and led to different political conceptions for their processes of independence, monarchy and republic, but that in the end, legitimized the maintenance of their respective previously existing socio-political elites. The use of sources for the case of Buenos Aires was established from biographical and manual works, their discussion, interpretation and analysis follows from the reflection and study on the theme in line with their initial perspectives.
\end{abstract}

Keywords: Rio de Janeiro; Buenos Aires; 1808. 
Portugueses! A vossa sorte é talvez a mais dura que povo algum tem sofrido. Vosso Príncipe se viu na precisão de deixar-vos, e o que aconteceu com a Espanha tem fornecido a mais indubitável prova da necessidade e absoluta daquela Resolução. Ordenaram que vós não defendêsseis, e vós não vos defendestes. Junot prometeu fazervos felizes, e a vossa felicidade tem consistido em vos tratar com maior crueldade que os maiores conquistadores jamais mostraram aos povos que venceram à força de armas, e depois da mais obstinada resistência. Despojaram-vos de vossos Príncipes, leis, usos costumes, bens, liberdade e até de vossas vias e de vossa Santa Religião, a qual vossos inimigos nunca respeitaram, ainda que segundo o seu costume prometessem protegê-la e afetassem conhecê-la. ${ }^{1}$

Em setembro de 1808, após a vinda da Corte Portuguesa para a América e dos acontecimentos do Prata, que levaram ao questionamento sobre a autoridade e legitimidade do monarca espanhol no Cabildo de Buenos Aires, a Gazeta do Rio do Janeiro apontava como principal fator para tais processos as investidas napoleônicas. Sem dúvida, essas ações, fizeram com que o mundo Ibérico sofresse transformações irreversíveis quanto à antiga estrutura política, organizada na relação colonial entre as metrópoles europeias e suas colônias do novo mundo. Desta forma, o ano de 1808 destaca-se como o principal divisor de águas para as futuras nações delineando o início de vários processos de emancipação política que se desenvolveriam na América. (MYERS, 2007: 69-92)

Pensar nestes momentos, despertou o interesse em entender os processos políticos e suas consequências para o Rio de Janeiro - cidade que a partir de 1808 tornou-se sede do Império Português - e para Buenos Aires, que com a crise da monarquia espanhola, tornou-se além de autônoma, centro político para as antigas províncias que formavam o Vice-Reino do Prata. Nesse processo histórico de comparação, buscou-se discutir sobre as semelhanças e diferenças que as duas regiões em questão apresentaram em seus respectivos projetos de independência, caracterizando assim a proposta de História Comparada elaborada por Marc Bloch. (BLOCH, 1998)

No caso português, a não adesão ao Bloqueio Continental, imposto por Napoleão em 1806, que visava extinguir as relações econômicas entre Portugal e Inglaterra, sua principal parceira econômica, além da iminente invasão ao território português em fins de 1807 por tropas franco-espanholas, fizeram com que o Príncipe Regente D. João, optasse por uma antiga alternativa de transferência da Corte portuguesa para sua principal colônia, o Brasil, com o intermédio e auxílio inglês. Essa iniciativa além de

\footnotetext{
${ }^{1}$ Gazeta Extraordinário do Rio de Janeiro. Rio de Janeiro, $\mathrm{n}^{\mathrm{o}} 1,14$ de setembro de 1808. Biblioteca Nacional.
} 
proteger a monarquia lusa desencadeou significativas mudanças para o status quo vivido no Brasil. O espaço colonial brasileiro foi aos poucos sendo transformado no espaço político da metrópole. (DIAS, 1972: 160-184)

No caso espanhol, com a invasão das tropas francesas em seu território, seguido pela conquista de Madrid e da abdicação forçada de Carlos IV e de seu filho Fernando VII, os antigos laços entre a Espanha e suas colônias americanas foram desgastados. Destacam-se dois movimentos em decorrência dessa invasão: o primeiro uma Junta Central de Governo que tentou resistir aos franceses e foi reconhecida pela maioria dos Vice-Reinados, Capitanias Gerais e Províncias, mas que não obteve êxito e caiu em 1810. E, o segundo iniciado em 1809, que pretendia à criação de Juntas autônomas de governo em diferentes cidades desse Império, principalmente, na porção americana e que ganhou força e espaço com a queda de Sevilha e dos representantes Bourbons espanhóis. $^{2}$

Portanto, o ano de 1808 apresenta-se como fundamental para a criação de novos espaços políticos na Iberoamérica, guardando a semelhança das causas que levaram a tais mudanças, mas permitindo uma proposta distinta de projetos. Enquanto o Brasil continuava a manter certos vínculos com a metrópole na esfera política, já que seus representantes reais aqui se instalaram, na América espanhola ocorreu uma cisão, pois apesar de que algumas regiões mantiveram lealdade à monarquia espanhola, outras, como as Juntas que compunham a região do Prata e, principalmente Buenos Aires, eram a favor da criação de um sistema autônomo de governo, por meio de uma república representativa, colocando assim em xeque a antiga legitimidade política. (CHIARAMONTE, 2007: 59-89)

Pode-se refletir que a crise de legitimidade da política colonial ocorreu antes na Região do Prata, graças as invasões inglesas de 1806 e 1807. A resistência exercida pelos habitantes da região as tais ações possibilitaram maior liberdade econômica colocando Buenos Aires à frente na hierarquia administrativa do referido Vice-Reino. (VERDO, 2008: 37-64)

\footnotetext{
${ }^{2}$ Além de Jorge Myers. A Revolução de Independência no Rio da Prata e as Origens da Nacionalidade Argentina (1806-1825). Op. cit., pp. 69-92. Outros autores também apontam para a importância de 1808 como: GUERRA, François-Xavier (1999/2000). A nação na América espanhola: a questão das origens. Revista Maracanan. Rio de Janeiro, I, (1); CHIARAMONTE, José Carlos (2004). Nación y Estado em Iberoamérica. El lenguage político em tiempos de las independências. Buenos Aires: Editorial Sudamericana; GOLDMAN, Noemí (2005). Nueva Historia Argentina: Revolución, República, Confederación. (1806-1852). Buenos Aires: Editorial Sudamaricana; PIMENTA, João Paulo (2006). Estado e Nação no Fim dos Impérios Ibéricos no Prata (1808-1828). São Paulo: Hucitec.
} 
O fato foi que esta invasão repercutiu na formação dos movimentos de "corpos milicianos voluntários", compostos por espanhóis dos dois lados do Atlântico, que tinham o objetivo de retomar Buenos Aires, levando à uma rápida militarização da sociedade rio-platense e, por conseguinte, na própria crise da legitimidade da ordem colonial, com a crescente autonomia do Cabildo de Buenos Aires e de sua elite criolla. (GOLDMAN, 2005: 25-31; DONGUI, 2007: 19-46)

Tengo el honor de manifestar a la faz de todo el mundo, las gloriosas acciones de mis paisanos en la presente guerra con el Britano. Y a vista de Ella ¿ tendrá este frente para decir que el valor de los españoles europeus há degenerado en los Americanos? No, señores: más de doce mil testigos presenciales puedo producir que, a una voz, publican que jamás han visto mayor intrepidez, valor y ardimiento que el que experimentaron en los gloriosos hechos de armas del 12 de agosto de 1806, 12 de mayo, 7 de junio, 2,3,4,5 y 6 de Julio de 1807, y por todos quisera que hablase el teniente Coronel Del Regimento No58, Señor Enrique Cádogan, que habiendo experimentado, muy a su costa, el animoso denuedo de los Patrícios de Buenos Aires, preguntaba con asombro, después de rendido, por la tropa de escudo en el brazo, que por valiente y animosa había admirado a él y a los suyos. ${ }^{3}$

Esse movimento de militarização da sociedade apontou para dois importantes fatores: um para a sobrevivência da sociedade que se organizava e o segundo, a busca de sua autonomia tanto ao invasor inglês, quanto as decisões impostas pela metrópole espanhola. Mesmo ainda não delineando um ideário de separação, já apresentava a especificidade de Patrícios de Buenos Aires, ou seja, uma perspectiva de pertencimento local.

\footnotetext{
${ }^{3}$ Cornélio Saavedra. Proclama, Buenos Aires, 30 de diciembre de 1807. In: TITTO, Ricardo J. de (2009). El pensamiento de los hombres de Mayo. Buenos Aires: El Ateneo, p. 35. O trecho correspondente na tradução é: "Tenho a honra de manifestar à face de todo mundo, as gloriosas ações de meus compatriotas na presente guerra com a Inglaterra. E em vista desta $i$ terá este frente para dizer que o valor dos espanhóis europeus tem degenerado nos Americanos? Não, senhores: mais de doze mil testemunhas presenciais podem produzir que, a uma voz, publicam que jamais tenham visto maior intrepidez, valor e intusiasmo o qual experimentaram nos gloriosos datas de armas do 12 de agosto de 1806, 12 de maio, 7 de junho, 2,3,4,5 e 6 de Julio de 1807, e para todos quisera que falasse o tenente Coronel Do Regimento $\mathrm{N}^{\circ} 58$, Senhor Enrique Cádogan, que tendo experimentado, muito a sua costa, o animoso denuedo dos Patrícios de Buenos Aires, perguntava com assombro, após de ser rendido, pela tropa de escudo no braço, que por valente e animosa tinha admirado a ele e aos seus."
} 
Em 1810, Buenos Aires vivenciou uma experiência política que marcou seu processo de autonomia, a Revolução de Maio. Cisneiros, Vice-Rei que representava a Região do Prata foi destituído, estabelecendo-se de forma interina o Cabildo de Buenos Aires como encarregado de governar as demais províncias da região. No dia 25 de maio de 1810 , foi organizada uma assembleia política formada pelos principais moradores da cidade, cujo intuito foi nomear uma junta autônoma de governo, presidida por Cornélio Saavedra, Comandante do Regimento de Patrícios das Milícias. Esse fator foi em direção contraria a decisão das demais cidades americanas que aderiram ao movimento das juntas autônomas de governo, Buenos Aires não era mais governada por um representante do antigo poder colonial. (CHIARAMONTE, 2007; GOLDMAN, 2005)

La Junta Provisional Gubernativa de la Capital Del Rio de la Plata a los habitantes de Ella y de las demás províncias de Su Superior Mando, proclama:

Tenéis ya estabelecida la autoridad que remueve la incertidumbre de las opiniones, y calma todos los recelos. Las aclamaciones generales manifestan vuestra decidida voluntad; y solo ella há podido resolver nuestra timidez a enargarnos Del grave enpeño a que nos sujeta el honor de la elección. Fijad, pues, vuestra confianza y aseguraos de nuestras intenciones. Un deseo eficaz, un celo activo, y una contracción viva y asidua a proveer por todos los médios posibles la conservación de nuestra Religión Santa, la observância de las Leyes que nos rigen, la común posteridad y el sostén de esas Posesiones en la más constante fidelidad y adhesión a nuestro amado Rey y Señor Don Fernando VII y sus legítimos sucesores de la corona de España. ¿No son éstos vuestros sentimientos? Esos mismos son los grandes objetos de nuestros conatos. Reposad en vuestros desvelos y a la más estrecha unión y conformidad recíproca en la tierna efusión de estos afectos. Llevad a las províncias todas de nuestra dependência, y aún Allá, si puede ser hasta los últimos términos de la tierra, la persuasión del ejemplo de vuestra cordialidad y del verdadero desinterés con que todos debemos cooperar a la consolidación de esta importante obra. Ella afianzará de un modo estable la tranqüilidade y bien general a que aspiramos. ${ }^{4}$

\footnotetext{
${ }^{4}$ Proclama de la Primera Junta de Gobierno, 26 de mayo de 1810. In: TITTO. Op. cit., p. 96. O trecho correspondente na tradução é: “A Junta Provisória Governativa da Capital do Rio da Prata aos seus habitantes e das outras províncias do seu Alto Comando, proclama: Tens já estabelecida a autoridade que remove a incerteza das opiniões, e acalma a todos os receios. As aclamações gerais manifestam vossa decidida vontade, e só ela ha de resolver nosso temor de nos
} 
Destacava-se, nesse processo, a Revolução de Maio, o jovem advogado e político e um dos principais participantes, Mariano Moreno, que foi de secretário da Primeira Junta. Moreno também foi redator do primeiro periódico político de Buenos Aires, La Gaceta, e idealizador da Biblioteca Nacional da Argentina. Nesse cenário político percebe-se que a Imprensa e, principalmente, La Gaceta, como importante agente formador de um pensamento e de transformações políticas. (GOLDMAN, 2005: 42)

Enquanto isso, o Brasil ganhava ares de metrópole, significativas medidas transformaram o Rio de Janeiro de antiga capital colonial em sede da Corte Portuguesa. A abertura dos portos em 1808, o Tratado de Aliança e Comércio em 1810, a criação do Banco do Brasil, as Missões Artísticas e Culturais, a Impressa Régia, dentre outros acontecimentos demonstravam as necessidades que os representantes da Corte portuguesa precisavam para estabelecer a administração política desse lado do Atlântico., Tais transformações contribuíram, sem dúvidas, para o processo de independência realizado em 1822.

Neste respectivo corte cronológico explicitado, a imprensa realizada no Brasil no pós independência, também se apresentava como um espaço de discussão e de formação do pensamento político, construindo uma opinião para as diversas camadas sociais, mesmo sendo elaborada pela boa sociedade $e^{5}$, já que grande parcela da população estava distante da cultura letrada. No entanto, essa parcela iletrada era atingida indiretamente pelas leituras em voz alta nos espaços comuns. Assim, a imprensa tornava-se um importante meio para as ideias e práticas políticas, possuindo um caráter político pedagógico. (MOREL, 2005)

A título de comparação nesse interregno de tempo, tanto o Rio de Janeiro, quanto Buenos Aires legitimaram suas posições centrais frente à sociedade. Pois, eram

enganarmos do grave empenho que nos sujeita a honra da eleição. Corrigir o seu, portanto, a sua confiança e certifique-se de nossas intenções. Um desejo eficaz, zelo ativo, e um assíduo contração vivo e fornecer para todos os meios possíveis para a conservação de nossa santa religião, a aplicação das leis que nos regem, a posteridade comum e com o apoio das pessoas nas possessões mais constantes fidelidade e apego ao nosso amado Rei e Senhor D. Fernando VII e seus sucessores legítimos para a coroa de Espanha. Não são estes os vossos sentimentos? O mesmo são os grandes objetos de nossas tentativas. Permanecer em seus trabalhos, na mais estreita união e conformidade reciproca no concurso mútuo dessas afecções. Levar à todas as províncias de nossa união, e até lá, se pode ser até os últimos confins da terra, a persuasão do exemplo de sua bondade e verdadeira abnegação com que todos nós devemos colaborar na construção deste importante trabalho. Ela vai reforçar em uma tranquilidade estável e bem geral e o que aspiramos."

5 Para a expressão em grifo ver MATTOS, Ilmar R. de (1987). O Tempo de Saquarema. São Paulo: HUCITEC, p.113-120. 
regiões de destaques nas antigas estruturas coloniais e se mantiveram, pelo seu poder político, na vanguarda das decisões políticas, mantendo assim sua posição.

Enquanto sedes, contudo, se diferiram quanto aos projetos destinados: o Rio de Janeiro ocupou a posição de sede política do Império Luso, conservando a monarquia e a casa de Bragança ativa frente às decisões políticas, enquanto Buenos Aires já a partir de 1810 construía seu processo de autonomia frente ao império espanhol.

Outro fator político a ser considerado é a crise do Antigo Regime e o advento da política moderna. Quando a Coroa portuguesa optou pela vinda da Corte para sua colônia brasileira o pacto estabelecido entre o rei e seu reino foi quebrado, pois alterava seu lócus de poder. O pacto entre a coroa hispânica e Buenos Aires também se desfez a partir do momento em que se estabeleceu a abdicação forçada de Fernando VII, acarretando maior autonomia do Cabildo de Buenos Aires e o fim do governo monárquico para o Prata.

Mesmo diante das modificações entre os anos de 1808 e 1810, com distintos caminhos para as sociedades em questão, podem ser citadas algumas permanências. Apesar do Brasil ter ganho ares de metrópole e uma nova estrutura político-econômica que pudesse abarcar as transformações que a Corte exigia, tais "benesses" não trouxeram de início uma concepção de autonomia, pelo contrário era mantido o Império Luso, porém com o estabelecimento da Corte na América.

Frente às permanências que despontam em Buenos Aires, observa-se a manutenção das antigas elites coloniais no poder, ou seja, a importância da elite criolla. Entretanto, as propostas diferenciavam-se quanto às estruturas políticas, nas quais o Cabildo apresentava sobre autonomia e na possibilidade da criação de uma república.

A proposta de uma república não foi a única seguida pelos indivíduos que compunham a sociedade de Buenos Aires. Dentre outras alternativas políticas, destacase o "carlotismo", pensada por parte da elite criolla e pelo Vice-Rei Liniers, como solução para a crise da monarquia espanhola. Era uma maneira de controlar os processos de autonomia local, a partir de uma regência, que devia ser governada por Carlota Joaquina, irmã de Fernando VII. Tal medida poderia manter a antiga unidade do mundo hispânico. Carlota Joaquina também possuía interesses frente à possibilidade de controlar a Região do Prata e era entendida por parcela das elites do Vice-Reino do Prata como uma possibilidade de manter a unidade política da Região. (GOLDMAN, 2008: 8-9; GOLDMAN, 2005: 36-37; TERNAVASIO, 2005: 77-90) 
Señora:

El Virrey y Capitán de estas províncias del Rio de la Plata me há dirigido ya las actas públicas y reclamaciones que con motivo de los violentos e injustos procedimientos del emperador Napoleón se sirvieron Vuestras Altezas Reales y la del serenisimo señor infante Pedro de Borbón y Braganza, dirigir a todos los jefes de esta América, cuyo recibo le contesté con fecha 27 de noviembre de este año de 1808. Ahora posteriormente He recebido otros tantos con varios impresos de las noticias comunicadas de España que de orden de V.A.R. me remite directamente el secretario de los negócios extranjeros y de guerra de S.A.R. el Príncipe Regente de Portugal en carta de 24 de agosto de este mismo. $\mathrm{Y}$ en su consecuencia he creído deber asegurar, como aseguro a V.A.R. con mi más profundo respeto y reconocimiento, que cuando me há hecho el honor de esperar que yo y la província de mi mando imitemos la gloriosa resolución de la España en sostener los sagrados derechos de la religión Del Rey, de la real família y de nuestra libertad, me há hecho también justicia; porque desde el momento en que tuve la noticia de lo obrado en Bayona con nustro augusto soberano el Señor Don Fernando VII y con todas las personas de la real família que fueran alli conducidas con un engaño tan inócuo como cobarde, anticipé de acuerdo con esta fidelísima ciudad capital la jura y proclamación solemne de Señor Don Fernando VII por Rey de España y de las Índias, sellando con este acto la obligación que nos impone nuestra insigne fidelidad y patriotismo. ${ }^{6}$

O interesse no Vice-reino do Prata era uma questão notória, não só para Carlota Joaquina mas também para seu marido o Príncipe Regente D. João, que via como uma

\footnotetext{
${ }^{6}$ Ramón Gracía Pizarro, presidente de Charcas Oficio em respuesta a la Princesa Carlota Joaquina de Borbón, 25 de diciembre de 1808. In: TITTO. Op. cit., p. 52-53. O trecho correspondente na tyradução é: "Senhora: O vice-rei e capitão desta província entre o Rio de la Plata me tenho dirigido as atas públicas e reclamações afirmo que, devido ao processo de violentas e injustas do Imperador Napoleão é servido Altezas Reais e sereno Senhor D. Pedro de Bourbon e Bragança, dirigir a todas as chefes desta América, o recebimento conteste com data de 27 de novembro deste ano de 1808. Agora posteriormente recebi nenhum muitos outros com várias formas de notícias relatadas a partir de Espanha que a ordem V.A.R. me remete diretamente Negócios Secretário de Guerra estrangeira e S.A.R. o Príncipe Regente de Portugal em carta de 24 de agosto do mesmo. E, em conseqüência me senti obrigado a garantir, como V.A.R. assegurar com o meu mais profundo respeito e reconhecimento, que, quando eu tive a honra de esperar e na província de meu comando imitar a gloriosa resolução de Espanha para manter os direitos sagrados da religião Del Rey, da família real e da nossa liberdade, a justiça também me fez ha para a partir do momento em que a notícia de que havia trabalhado em Bayonne nosso augusto soberano Senhor Don Fernando VII e todas as pessoas da família real que lá estavam realizou uma decepção tão inócuo como covarde antecipado sob este capital fidelísima o juramento e proclamação solene pelo Sr. D. Fernando VII, Rei de Espanha e das Índias, selando com este ato impõe uma obrigação que a nossa lealdade distinto e patriotismo."
} 
possibilidade de ampliar o vasto território continental brasileiro. Questões políticas, entretanto, que implicaram no fim do apoio inglês à causa e à própria resistência em ter como representante político uma personagem atrelada ao império português, levaram ao fim dos interesses de Carlota Joaquina. A possibilidade da instauração de tal regência extinguiu-se pela falta de apoio e de interesse que o próprio Cabildo, como pode-se compreender na atitude do Vice-rei Liniers, que reforçou os laços de fidelidade a Fernando VII. (SOUZA, J. 1993: 303-306)

No entanto, a proposta de uma autonomia local ganhava cada vez mais expressão como pode-se observar pelas reflexões realizadas pelos revolucionários de maio de 1810, em decorrência do processo de crise da monarquia espanhola, que compreendiam epensavam a questão do comércio, da administração política e do sentimento local. Assim como destacou a Circular de la Junta de 3 de diciembre de 1810, que pretendia defender os indivíduos originários do Cabildo, frente aos interesses estrangeiros, indicando assim, um sentimento local e não mais a concepção de unidade composta pelo mundo espanhol:

Los funestos desengaños que há recibido esta Junta de hombres ingratos al país, en que hicieron su fortuna, y que los volvería infelices con arrojarlos de su seno, la precisam a tomar aquellas medidas que puedan asegurar la conservación y bien de la tierra, por los estímulos que la misma naturaleza inspira a los que han nacido en Ella. Las naciones todas justifican esta regla con su conducta, pues en ninguna se divide el gobierno con hombres extraños, ni se dispensan los derechos de ciudad con una franqueza que haga menguar su estimación y aprecio.

$1^{\circ}$ Desde la Fecha de esta providencia ningún tribunal, corporación, o jefe, civil, militar, o eclesiástico, conferirá empleo público a persona que no haya nacido en estas províncias.

$2^{\circ}$ Toda pretensión de empleo será rechazada por el secretario o escribano ante quien se presente, mientras no se instruya como primero y esencial documento con la Fe de bautismo, que acredite haber nacido el pretendiente en estas províncias. ${ }^{7}$

\footnotetext{
${ }^{7}$ Circular de la Junta "Los derechos de los hijos del país". 3 de diciembre de 1810. In: TITO. Op. cit., p. 109-110. O trecho correspondente na tradução é: "As Sombrias desilusões tem os homens deste ingrato Conselho recebido do país, em que fizeram sua fortuna, e que os colocariam infelizes com sua origem, precisam de tomar qualquer medida susceptível de garantir a preservação e o bem da terra, para a estímulos que a natureza inspira aqueles que nasceram nela. As nações todas justificam esta regra com a sua conduta, para lugar nenhum é dividido governo com homens estranhos, ou dispensada direitos de
} 
Devia-se cada vez mais estar dissociado ao antigo império espanhol, a representatividade e o sentimento local ganhavam espaço e força. Assim, os estrangeiros favoráveis ao Cabildo, estes eram bem vistos e, assim, podiam ocupar seu lugar frente ao governo como apresenta o artigo quinto da mesma circular. "5 ${ }^{\circ}$ Los ingleses, portugueses, y demás extranjeros que no estén en guerra com nosotros podrán trasladarse a este país francamente: gozarán todos los derechos de ciudadanos, y serán protegidos por el gobierno los que se dediquen a las artes y ala cultura de los campos."8

Tal posição também reforçava o não interesse dos deputados de Buenos Aires em participar das Juntas propostas pelo governo resistente em Cádiz, local no qual a monarquia espanhola se refugiara e mantinha sua resistência frente ao governo de José Bonaparte. Essa reformulação política desejava reunir os deputados das referidas Juntas do mundo hispânico, congregando os representantes coloniais e espanhóis para a reestruturação do Império espanhol, a partir das propostas elaboradas e discutidas nas Cortes de Cádiz.

A união das Cortes foi um dos fatores que desencadeou o processo de autonomia de Buenos Aires, pois o movimento em questão, que deveria colocar, em igualdade de representatividade política, deputados peninsulares e americanos, na verdade não teve êxito, pois a representatividade foi favorável aos metropolitanos, maioria naquela instituição. Ao privilegiar certo grupo de indivíduos políticos, o descrédito foi notório por parte de Buenos Aires, que compreendeu este ato como uma simples forma de garantir os interesses do Rei e não repensar o Império espanhol. Logo, as investidas de Cádiz não foram implementadas em Buenos Aires, que procurava estruturar sua autonomia política. (TERNAVASIO, 2005: 77-90)

O processo revolucionário desencadeado em Buenos Aires a partir de 1810 pode ser dividido em dois momentos. O primeiro, entre 1810 e 1814, foi marcado pela influência direta de Mariano Moreno, em prol de total autonomia política e a favor do

cidade com uma franqueza que torna a sua estima e apreço minguar. $1^{\circ}$ A partir da data desta decisão qualquer tribunal, empresa ou chefe, civil, militar ou eclesiástico, deverá conferir para ocupar emprego público se pessoa não tenha nascido nestas províncias. $2^{\circ}$ Toda pretenção de trabalho será rejeitado pelo secretário ou escrivão diante de quem o apresenta, enquanto não instruir como primeiro e essencial documento da Fé Batismal, afirmando que o pretendente nasceu na respectiva província."

${ }^{8}$ Ibidem. Circular de la Junta "Los derechos de los hijos del pais". 3 de diciembre de 1810, p. 110. O trecho corresponte na tradução é: "Os ingleses, portugueses e demais estrangeiros que não estão em guerra conosco poderam transladar-se sem problemas por este país: gozaram de todos os direitos de cidadãos e serão protegidos pelo governo os que se dedicam as artes e a agricultura." 
republicanismo. O segundo expressa a vitória do conservadorismo, entre 1815 e 1820 , com a elaboração do Diretório como estrutura política governamental. Sendo também um momento de grande cisão e confrontos armados entre as diversas províncias que compunham o Vice-Reino do Prata, que procuravam elaborar suas leis e, por conseguinte, sua autonomia (GOLDMAN, 2005: 45-48). ${ }^{9}$

Vale destacar a importância de Mariano Moreno como um intelectual frente ao processo de autonomia de Buenos Aires. Suas ações - sejam elas como redator da Gazeta de Buenos Aires ou como idealizador da Biblioteca Nacional, seus escritos de cunho político, bem como sua reflexão sobre o conhecimento a ser apreendido pela sociedade a partir da instrução, apontavam para um caminho de autonomia para Buenos Aires, influenciando outros indivíduos para a construção da Nação.

La utilidad de los discursos de hombres ilustrados y que sostentan y didriján el patriotismo y fidelidade, que tan heroicamente se há desplegado, nunca es mayor que cuando el choque de las opiniones pudiera envolver em tinieblas aquellos princípios, que los grandes talentos pueden unicamente reducir a su primitiva claridade; y la junta, a más de inicitar ahora generalmente a los sabios de estas províncias, para que escriban sobre tan importantes objetos, los estimulará por otros médios que les descubram la confianza que pone en sus luces y en su celo. ${ }^{10}$

Desta forma, para Moreno somente através do conhecimento útil, ou seja, aquele capaz de promover transformações a sociedade de Buenos Aires alcançaria sua autonomia. O conhecimento de certa forma traria a condição necessária para dinamizar as transformações políticas.

\footnotetext{
${ }^{9}$ Quanto ao período denominado Diretório foi o momento em que Buenos Aires legalmente era o centro político e controlava as demais províncias que compunham tal estrutura política, marcada pelo conservadorismo de seus representantes e por vários conflitos armados que visavam a emancipação de certas províncias, que compunham o antigo Vice-Reino do Prata.

${ }^{10}$ Mariano Moreno. Fundación de "La Gaceta". In: ROMERO, Ricardo (2008). Mariano Moreno: politica y gobierno en su pensamento. Buenos Aires: Ediciones Cooperativas, p. 191. O trecho correspondente na tradução é: "A utilidade dos discursos dos homens ilustrados e que sustentam e dirigem o patriotismo e fidelidade, que foi implantado tão heroicamente nunca é maior do que quando o choque de opiniões poderia envolver na escuridão esses princípios, que os grandes talentos só pode unicamente reduzir a sua clareza original, e a junta, incitando mais agora geralmente para os sábios destas províncias, para que escrevam sobre tão importantes objetos, irá incentivar outros meios que os descubram a confiança que põem em suas luzes e em seu zelo.”
} 
Em 1811, mesmo após a morte de Moreno, suas ideias e influência permaneceram vivas graças a seus partidários, que, por meio de críticas a Saavedra ${ }^{11}$, mantinham o pensamento morenista vivo frente à Sociedade Patriótica, que assistia com certa insegurança à militarização imposta pelo governo em vigor. A petição escrita, em 6 de abril de 1811, descrevia tal cenário, além da vontade de se findar os vínculos com a Europa, para legitimar sua autonomia. Ainda pairava o temor de uma reaproximação com a Espanha, que, naquele momento, mantinha seus representantes em Cádiz, resistindo e organizando uma nova Constituição para o mundo espanhol, como pode-se observar nos seguintes artigos abaixo:

Primera: Convencido el pueblo de Buenos Aires de que las medidas adoptadas hasta el dia para reconciliación de los Espanõles Europeus Americanos, son a más de ineficaces, perjudiciales a la gran causa y sistema de gobierno que se sigue, y debe abrazarse en lo venidero; es su voluntad que se expulsen de Buenos Aires a todos los Europeos de cualquer clase o condición, no acreditando de un modo público, y que sirva de satisfacción al Pueblo, que han sido unânimes y conformes a sus sentimientos, y opiniones, desde la instalación de su nueva forma de gobierno por lo que respecta al enunciado sistema.

Quinta: Es de derecho indudable, que cuando el Pueblo no há dado sus poderes y faculdades expresamente para el nombriamento de los indivíduos que deben regirlo y gobernalo por efecto de los que tênia instituídos de antemano, todo acto de jurisdiccíon ejecutado en contra es una usurpación manifesta de su autoridad con transgresión de los limites de su voluntad: de consiguiente no sólo nulo y de ningún valor, sino también preparatório del despotismo y esclavitud a que se quiere reducir la libertad de lós demás Ciudadanos. ${ }^{12}$

\footnotetext{
${ }^{11}$ Cornélio Saavedra foi o comandante dos patrícios contra os ingleses em 1806 e 1807, também participou como um dos revolucionários de Mayo em 1810, sendo após a constituição do cabildo aberto Saavedra foi o primeiro Presidente da Junta de Buenos Aires.

${ }_{12}^{2}$ Peticion Popular Del 6 de Abril de 1811. In: ETCHART \& DOUZON (1989). Documentos de Historia Argentina (Selección). Buenos Aires: Cesarini HNOS - Editores, p. 16-18. O trecho correspondente na tradução é: "Primeiro: convenceu o povo de Buenos Aires que as medidas tomadas até agora para reconciliação dos Espanhóis Europeus Americanos são mais do que ineficaz, prejudiciais à grande causa e sistema de governo que se segue, e que se deve abraçar no futuro; sua vontade será que se expulsem de Buenos Aires a todos os europeus de qualquer classe ou condição, não comprovando de forma pública, e para servir como uma satisfação ao povo, que esta sendo unânime e de acordo com os seus sentimentos e opiniões, desde a instalação a sua nova forma de governo no que diz respeito ao anunciado sistema. Quinto: É de direito inquestionável, que, quando ao povo não têm dado os seus poderes e expressamente faculdades para a nomeação dos indivíduos que devem reger-lo e governá-lo efetivamente daqueles que
} 
Era fundamental a manutenção e a luta pela autonomia. Voltar a condição de parte integrante do império espanhol seria retroceder ao universo do despotismo e da escravidão, termos que não estariam de acordo com a proposta de liberdade e cidadania que assim se desejava para Buenos Aires.

A efervescência política continuava e, em 1812, depois de seis tentativas de governos revolucionários, instaurou-se o primeiro Triunvirato, que, nas palavras de Noemi Goldman, não foi melhor sucedido politicamente que o seu antecessor, a Junta conservadora. Também, naquele momento, apresentou-se a volta do Club Morenista, com o nome de Sociedade Patriótica, tendo à frente o político e amigo de Moreno, Bernardo Monteagudo ${ }^{13}$ que seguiu os passos do antecessor frente à Gazeta de Buenos Aires e Mártir o Libre, periódicos em que foi redator. Sua intenção era declarar a Independência e elaborar a Constituição. (GOLDMAN, 2005: 50-51)

¿Por qué funesto trastorno há venido a ser esclavo ese árbitro subalterno de la naturaleza, cuya voluntad solo debía estar sujeta a las leyes que sancionan su independencia y señalan los limites que la razón eterna tiene derecho a prescrebir? ¿Por qué há vivido el hombre entregado a la arbitrariedad de sus semejantes y obligado a recebir la ley de un perverso infeliz? ¿No busquemos la causa fuera del hombre mismo: la ignorância lo hizo consentir en ser esclavo, hasta que con el tiempo olvido que era libre: llegó a dudar de sus derechos, vacilo sobre sus princípios y perdió de vista por una consecuencia necesaria el cuadro original de sus deberes. Un extraño embrutecimiento vino a colocarlo entre dos escollos tan funestos a la justicia como a la humanidad; y fluctuando entre la servidumbre y la licencia mudaba algunas veces de situación, sin mejorar su destino siempre desgraciado, y acuando traspasaba los limites de su Libertad, y acuando gemia en la esclavitud.

[...] Por esto He mirado siempre com admiración la Libertad de Esparta, y no sé cómo podían lisonjearse de ser tan libres, cuando por outra parte sostenían

tinham instituído anteriormente, qualquer ato de jurisdição é executada contra uma usurpação sua autoridade manifesta transgressão dos limites de sua vontade, de despotismo, não só, portanto, nula e de nenhum valor, mas também de preparação e escravidão a que você quiser reduzir a liberdade dos outros cidadãos."

13 Bernardo de Monteagudo nasceu em Tucumán em 20 agosto de 1789, se formou em direito pela Universidade de Chuquisaca, junto com Mariano Moreno. Foi redator da Gazeta de Buenos Aires, após a morte de Moreno e do periódico Mártir o Libre. Também pode ser visto como um importante intelectual que contribui para o processo de autonomia de Buenos Aires. 
la esclavitud de los ilotas, aunque Sócrates les atribuía las ventajas de un estádio médio. Ello es que la existência de un solo siervo en el Estado más libre, basta para marchitar la Idea de su grandeza. !Felices las comarcas donde la naturaleza vê respetados sus fueros, en el más desvalido de los mortales! ${ }^{14}$

Portanto Monteagudo insistia que não só a liberdade estava em questão para Buenos Aires, mas também a integração de um novo governo que condensaria as demais regiões que compunham o antigo Vice-Reino em prol de uma unidade. O intuito só se concretizou depois do segundo Triunvirato, no período político denominado Diretório, em 1816, a partir da formação do Congresso General Constituinte de las Provincias Unidas em Sudamérica, presidido por Juan Martín de Pueyrredón, que afastou por completo qualquer possibilidade de uma nova organização monárquica no Prata, concentrando nas mãos dos indivíduos mais importantes das elites que compunham a sociedade de Buenos Aires, a nova estrutura política a ser seguida por meio de um ideal republicano. (GOLDMAN, 2005: 21-70)

Assim, como pode-se destacar na citação abaixo, romper os laços com a Espanha era estar em consonância aos acontecimentos e interesses estabelecidos no Congresso Geral, representando de fato a autonomia desejada.

Nos, los representantes de las Províncias Unidas en Sud América, reunidos en Congreso General, invocando o Eterno que preside al universo, en el nombre y por la autoridade de los Pueblos que representamos, protestando al cielo, a las naciones y hombres todos del globo, la justicia que regla nuestros votos: Declaramos solemnemente a la faz de la tierra que es voluntad

\footnotetext{
${ }^{14}$ Bernardo de Monteagudo. Mártir o Libre. 21 de febrero y 6, 20 y 29 de marzo de 1812. In: TITTO. Op. cit., p. 200-202. O trecho correspondente na tradução é: "Por que o funesto transtorno veio ser escravo esse subalterno árbitro da natureza, cuja vontade só deve estar sujeito às leis que sancionam a sua independência e apontar o da razão eterna tem direito a prescrever? Por que tem vivido o homem a entregar-se à arbitrariedade de seus semelhantes e forçado a receber uma lei perversa infeliz? Não busque a causa fora do próprio homem: a ignorância o fez consentir em ser escravo, até que finalmente com o esquecimento que estava livre: chegou a duvidar de seus direitos, hesitar sobre seus princípios e perdeu de vista, por consequencia, suas necessárias atribuições originais. Um estranho embrutecimento veio colocar-lhe entre as armadilhas fatais para a justiça e para a humanidade, e oscilou entre a servidão e a licença de caminhar situação algumas vezes, sem melhorar o seu destino sempre desgraçado, e quando foi além dos limites de sua Liberdade, e quando gemeu na escravidão. [...] É por isso que eu sempre olhei com admiração a Liberdade de Esparta, e eu não tem como lisonjear-se por serem tão livre, quando por outro lado sustentavam a escravidão dos hilotas, embora Sócrates tenha lhes atribuído as vantagens de um estágio intermediário. É por isso que a existência de um único escravo no Estado mais livre, e o suficiente para manchar a ideia de sua grandeza. ! Felizes das regiões onde a natureza e respeitados seus foros, e desta forma também os mais desvalidos dos mortais."
} 
unánime e indudable de estas Provincias romper los violentos vínculos que las ligaban a los reys de España, recuperar los derechos de que fueram despojadas e investirse del alto caráter de una Nación libre e independiente del Rey Fernando VII sus sucesores y Metrópoli quedan en consecuencia de hecho y de derecho con amplio y pleno poder para darse las formas que exija la justicia, e impere el cúmulo de sus actuales circunstancias. ${ }^{15}$

Sobre o Rio de Janeiro, em 1808, tornou-se sede da Corte do império português. Tal fato desencadeou uma série de transformações políticas para a América portuguesa.

Vale destacar um importante ponto de aproximação entre o Rio de Janeiro e Buenos Aires do início do século XIX, refere-se ao interesse que a Inglaterra apresentou em ambas as regiões. No caso do Brasil, observa-se na assinatura dos Tratados de Abertura dos Portos em 1808 e de Aliança e Comércio de 1810, resultantes de uma antiga relação política e econômica entre esses países. Vale destacar também como novas dinâmicas propostas pela aliança Inglaterra - Portugal frente às investidas napoleônicas, o que levou a destituir à antiga estrutura de monopólio comercial, trazendo à tona uma nova dinâmica de comércio e, por fim, o termíno do pacto colonial.

Essas medidas tinham como principal intuito reforçar o interesse e a exploração inglesa na América do Sul. A parte portuguesa ocupava a principal dimensão, especialmente, após o fracasso inglês em dominar Buenos Aires, nos anos de 1806 e 1807. O apoio concedido à monarquia lusitana, frente aos avanços franceses e no momento do estabelecimento da corte no Novo Mundo, facilitou os objetivos da Inglaterra, que não eram necessariamente de um controle de caráter político, mas sim, principalmente, de viés econômico. (PANTALEÃO, 1993: 64-99)

Todas as transformações procuravam constituir à nova sede da Corte portuguesa, um ar de civilidade e de progresso. Foram incentivadas as missões artísticas e científicas que visavam ao conhecimento de tudo que a envolvesse. Estudar a fauna, a

\footnotetext{
${ }^{15}$ Acta de la Declaracion de la Independência Argentina. In: ETCHART \& DOUZON. Op. cit., p. 39. O trecho correspondente na tradução é: "Nós, os representantes das Províncias Unidas da América do Sul, reunidos em Congresso Geral, invocando o Eterno que preside o universo, em nome e pela autoridade dos povos que nós representamos, protestando para o céu, as nações e todos os homens do mundo, a justiça que regra os nossos votos: Declaramos solenemente na face da terra que é unânime e inquestionável desejo destas Províncias de romper os violentos laços que as ligam entre os reis da Espanha, para recuperar os direitos de que foram despojadas e investir no alto caráter uma Nação livre e independente do Rei Fernando VII e seus sucessores e da Metrópole, consequentemente de fato e de direito com amplo e pleno poder para dar se os caminhos exigidos pela justiça, imperando o conjunto de suas circunstâncias atuais."
} 
flora, os solos, retratar a sociedade e seus agentes recebiam o aval e interesse do Príncipe Regente D. João, inserindo o Rio de Janeiro em sua nova condição - sede do Império português. Nesse cenário a Biblioteca Real e sua criação apresenta-se como uma das formas de se representar a civilidade no novo Império luso-brasileiro.

No entanto, tais modificações, na sociedade brasileira, a princípio, não designaram uma vontade ou um processo de autonomia. Refletiam apenas, as condições básicas para se acomodar a monarquia portuguesa nos trópicos, frente a seus anseios e necessidades. Entretanto, em relação aos acontecimentos no Prata, principalmente os realizados em Buenos Aires, visavam ao fim da estrutura colonial. Desse modo, enquanto o Rio de Janeiro revestia-se de metrópole, em Buenos Aires, a discussão sobre a autonomia republicana florescia.

$\mathrm{O}$ ano de 1815 destacou-se, frente aos acontecimentos políticos da América portuguesa, por um importante fator que contribuiu para a sua autonomia: a elevação do Brasil à Reino Unido com Portugal e Algarves. Tal lei apontava para uma nova posição as terras portuguesas na América e alçava o Brasil para posição de importância frente ao mundo português como apontou em proclamação Antonio Morais Pinto, escrivão do 16 Senado à época, no periódico a Gazeta do Rio de Janeiro.

\section{Senhor}

A ilustrada política e espontânea deliberação, com que V.A.R. houve por bem elevar este estado do Brasil à preeminência de Reino, unindo-o debaixo de um só título ao de Portugal e Algarves, é o fausto motivo, que hoje conduz aos pés V.A.R. este Senado da Câmara, e alguns dos cidadãos desta capital, a fim de renderem as devidas graças a V.A.R. tanto por si, como em nome de todos os seus habitantes.

O Brasil, Augustíssimo Senhor, merecia aquela preeminência pela sua vastidão, fertilidade, e riqueza: A Mente esclarecida de V.A.R. o reconheceu: a paternal e augusta Mão firmou o liberalíssimo Diploma, a Carta de Lei de 16 de dezembro Corrente. Que inauferíveis direitos a nossa eterna gratidão! Que título a imortalidade! A PROVIDÊNCIA tinha reservado a V.A.R. esta glória. ${ }^{16}$

${ }^{16}$ Gazeta do Rio de Janeiro. Rio de Janeiro, no 3, 10 de janeiro de 1816. Biblioteca Nacional do Rio de Janeiro. 
O Brasil elevado a Reino Unido representava não só a importância dada à antiga colônia, como remetia a um significativo aspecto: a vontade de D. João em permanecer no Brasil e o papel que a parte do lado de cá do Atlântico recebia, pois, desde 1814, Napoleão Bonaparte já havia sido derrotado pelas monarquias europeias e, portanto, se D. João assim desejasse, poderia ter retornado a Portugal. Outro fator de destaque para a constituição do Reino Unido é a questão econômica que essa medida trouxe para as elites mercantis que viam nessa condição maior poder e prestígio, pois ampliou a liberdade comercial estabelecida por lei a partir da vinda da Corte. Ainda fortaleceu, sobretudo a condição de metrópole para a antiga colônia no Império Português advinda com a vinda da Corte.

Em relação a Buenos Aires, o ano de 1815 apresentava-se como o início do processo de autonomia completa, e, por conseguinte, sua independência frente à Espanha, como apresentado no Estatuto Provisional Para Direccion y Administracion Del Estado. Também demonstra o momento em que a cidade de Buenos Aires se apresentava como autoridade frente às demais regiões sendo a sede do poder central. (VERDO, 2008: 49)

O ano de 1816 foi para Buenos Aires o momento de declaração de Independência deste Cabildo frente ao mundo hispânico. Nesse processo, Buenos Aires estava aberta para a integração de outras províncias, que desejassem não mais fazer parte da tirania imposta às antigas colônias pelo Império espanhol. Assim, um novo congresso geral foi organizado na cidade de Tucumán, após a proclamação da independência das Províncias Unidas, visando redigir um texto constitucional. (MYERS, 2007: 77; CHIARAMONTE, 2007: 123)

Entre as decisões propostas no congresso de Tucumán, destaca-se um decreto que escolheu uma bandeira e as cores que simbolizariam a nação, que se constituía a partir daquele ano. Era um marco para que se unificassem as demais regiões que comporiam a futura nação com sede política em Buenos Aires. Assim, o próprio congresso espelhava a união entre as demais províncias a Buenos Aires, indicando, nesse sentido, que ainda se estava a caminho da união e da formação de uma Nação.

Elevadas las provincias Unidas en Sud América al rango de una nación, después de la declaratoria solemne de su independencia, será su peculiar distintivo la bandera celeste y blanca de que se ha usado hasta el presente, y se usará en lo sucesivo exclusivamente en los ejércitos, buques y fortalezas, 
en clase de bandera menor, ínterin, decretada al término de las presentes discusiones la forma de gobierno más conveniente al territorio, se fijen conforme a ella los jeroglíficos de la bandera nacional mayor. ${ }^{17}$

A questão da bandeira demonstrava que, apesar de caminhar a discussão sobre a independência, não havia ainda uma unidade entre todas as províncias que ocupavam o Prata, pois algumas visavam a sua própria autonomia, não desejando estar atrelada a Buenos Aires. Outras ainda almejavam fazer parte do mundo Hispânico.

Tal questão é fundamental para se comparar com o Brasil: a vinda da Corte portuguesa e as modificações que a mesma inseriu não agradaram a todas as províncias, que viam o Rio de Janeiro tornava-se o centro político administrativo do Império português deixando, muitas vezes, certas províncias como Pernambuco e Bahia como meros contribuintes para as finanças que deveriam manter o governo e a família real. $\mathrm{O}$ elemento que ajudou a manter a unidade territorial foi a monarquia, que precisou estar mais próxima das elites locais para que não ocorresse um desmembramento territorial, além de usar a força, quando necessário, como na Revolta de Pernambuco em 1817, para que não ocorresse uma fragmentação semelhante à do império espanhol na América (MAGNOLI, 2003: 285-293).

Ao se elaborar um paralelo com as Juntas do Prata, como indicou Luiz Geraldo Silva, a principal questão voltou-se para os confrontos frente aos peninsulares, já que os Criollos mantinham um conflito aberto contra os espanhóis. Entre os pernambucanos existia uma aproximação entre estes e os portugueses, que fossem a favor das prerrogativas pernambucanas, o que demonstra não uma questão de crítica sobre a origem e sim diferenças quanto as atitudes do soberano. (SILVA, L., 2005)

A administração com sede no Rio de Janeiro, também, foi questionada, anos mais tarde, por outras províncias, como o Pará e a Bahia, que mantiveram comunicação direta com Lisboa, no momento da convocação e discussão das Cortes em Portugal, ao longo do ano de 1821. Tais províncias aderiram de imediato ao movimento

\footnotetext{
${ }^{17}$ Decretos dados por el Congreso de Tucuman aprobando el uso de la bandera. In: ETCHART \& DOUZON. Op. cit., p. 40. O trecho correspondente na tradução é: "Elevadas as Províncias Unidas da América do Sul para a classificação de um país, após a solene declaração de independência, será a sua bandeira azul e branca distintivo peculiar, que tem sido utilizado até agora, e serão usados exclusivamente adiante anfitriões, navios e fortalezas, bandeira menor em sala de aula, entretanto, promulgada no final dessas discussões, a forma mais adequada de governo para o território, ele é definido de acordo com os hieróglifos da maior bandeira nacional."
} 
constitucional português, jurando fidelidade à futura Constituição, que devia ser elaborada pelo Congresso português. (BERBEL, 1999: 57-58)

A proximidade dessas províncias não ocorria somente em virtude dos interesses econômicos de comerciantes portugueses nelas estabelecidos, mas também em função de propostas políticas. As províncias do Norte acreditavam que os ideais de um governo liberal emanavam das Cortes portuguesas e não do governo sediado no Rio de Janeiro, que atuava por meio de uma centralização monárquica, nos moldes de uma administração opressora do Antigo Regime. (NEVES, 2003: 129-140)

Toda essa movimentação no Brasil ficou cada vez mais clara, a partir da discussão liberal que veio à tona com a Revolução Vintista ou Revolução Liberal do Porto, que tinha como objetivo estabelecer uma constituição que governasse o mundo luso, a volta da Corte portuguesa e a consequente centralização do império em Portugal, fato que não foi aceito por todos os representantes das Cortes, gerando um processo de crise política, na qual, a figura de D. Pedro despontou como um novo elemento político, para as elites situadas na América e de suas reivindicações político-econômicas. (CAMPUS, 1993: 331-378)

Nesse contexto, de início, D. Pedro reafirmou sua posição e a soberania de seu pai - o rei D. João VI. Essa atitude não colocava o Príncipe Regente como um intermediário entre o povo e as ideias liberais, mas sim como uma alternativa que pudesse evitar qualquer movimento de caráter revolucionário e com isso, manter suas condições de elites político-econômicas, sem que ocorresse total transformação social. Seguindo acontecimentos como "o Fico", o "Cumpra-se" dentre outros, observa-se que o processo de separação entre Portugal e o Brasil significou a vitória das elites do lado de cá do Atlântico, que não desejavam ter cerceados seus interesses pelas Cortes portuguesas.

Frente ao processo de independência deve-se enfatizar a importância de José Bonifácio de Andrada e Silva, que desponta como importante intelectual. Suas ações, frente as Cortes, suas atitudes enquanto ministro, favoreceram desde a permanência de D. Pedro I ao processo político que levou a ruptura política com Portugal, criando o centro de poder político na figura do Príncipe Regente e aproximando as elites, mesmo com posições políticas distintas. (CALDEIRA, 2002: 25-30)

Esses indivíduos escolheram D. Pedro para se tornar o Imperador e representante de seus interesses, a partir de elaboração de uma Monarquia Constitucional. A oficialização da independência foi estabelecida, mesmo a contragosto, de algumas 
províncias brasileiras, com a aclamação do príncipe regente em Imperador do Brasil, em 12 de outubro de 1822, sendo o 7 de setembro uma data histórica, criada a posteriore para marcar a ideia de separação política. ${ }^{18}$ Mas de certo, um último ponto de proximidade, destaca-se nesse sucinto trabalho, que teve como objetivo traçar algumas correlações e comparações entre o processo de independência Argentino e o Brasileiro. Mesmo com a instauração de uma república, com a origem da autonomia do antigo Cabildo de Buenos Aires, quanto de uma monarquia constitucional no Brasil, ambas foram constituídas pelos e aos interesses que as elites das respectivas sociedades em questão buscavam. Mantendo desta forma, seu poder e status quo, a partir de governos que assim lhes estruturassem, por meio de mudanças, que não extrapolassem a estrutura vigente de poder político e econômico. Observa-se essa dimensão ao se compreender por elite, em ambas sociedades, classes dominantes que possuíam o poder econômico, que em sua maioria eram letrados, e, por fim, também concentravam em suas mãos os poderes políticos. Sendo assim, optaram pela manutenção de seus interesses, legitimando sistemas governamentais que lhes pudessem, desta forma, favorecer.

\section{Fontes}

GAZETA DO RIO DE JANEIRO. Rio de Janeiro. 1808-1822. Fundação Biblioteca Nacional do Rio de Janeiro. Setor de Periódicos. PRSOR 00004 [1-8].

\section{Referências bibliográficas}

BERBEL, Márcia Regina (1999). A Nação como artefato: deputados do Brasil nas Cortes Portuguesas 1821-1822. São Paulo: HUCITEC/FAPESP, pp.57-58.

BLOCH, Étienne (1998). Marc Bloch. História e historiadores: textos reunidos por Étienne Bloch. Lisboa: Ed. Teorema.

CALDEIRA, Jorge (2002) (org.). José Bonifácio de Andrada e Silva. Coleção Formadoes do Brasil. São Paulo: Ed.34.

CAMPUS, Pedro Moacyr (1993). O Reconhecimento do Império. In: HOLANDA, Sérgio Buarque de. História geral da civilização brasileira. Tomo II: o Brasil

\footnotetext{
18 Sobre essa visão do Sete de Setembro, Cf. NEVES, Lucia Maria Bastos P. (2003). Corcundas e Constitucionais: a cultura política da independência. (1820-1822). Rio de Janeiro: FAPERJ, p. 369-370; LYRA, Maria de V. (1995). Memória da Independência: marcos e representações simbólicas. Revista Brasileira de História. São Paulo, 15(29): 173-199; LEITE, Renato Lopes (2000). Republicanos e Libertários. Pensadores radicais no Rio de Janeiro (1822). Rio de Janeiro: Civilização Brasileira; e NEVES, Lúcia Maria Bastos P. (1995). O Império Luso-Brasileiro redefinido: o debate político da independência (1820-1822). Revista do Instituto Histórico e Geográfico Brasileiro. Rio de Janeiro: 156: (387): 297-307, abr.- jun.; NEVES. Op. cit. A Vida Política, p. 96-97.
} 
monárquico: o processo de emancipação. Rio de Janeiro: Ed. Bertrand Brasil, pp. 331-378.

CHIARAMONTE, José Carlos (2004). Nación y Estado em Iberoamérica. El lenguagem político em tiempos de lãs independências. Buenos Aires: Editorial Sudamericana.

(2007). Ciudades, províncias, estados: Orígenes dela Nación Argentina (18001846). Buenos Aires: Emecé editores.

DIAS, Maria Odila da S (1972). A interiorização da metrópole (1808-1853). In: MOTA, Carlos G. (org.). 1822: dimensões. São Paulo, Perspectiva, pp. 160-184.

DONGUI, Tulio Halperin (2007). Historia Argentina: de la revolución de independência a la Confederación Rosista. Buenos Aires, Paidós.

ETCHART, Martha B. \& DOUZON, Martha C. (1989). Documentos de historia Argentina. Buenos Aires: Cesarini HNOS Editores.

GOLDMAN, Noemi (2008). Lenguaje y Revolución. Conceptos Políticos Clave en el Rio de la Plata, 1780-1850. Buenos Aires: Prometeo Libros, pp.19-31.

(2005) (dir.). Nueva Historia Argentina: Revolución, República, Confederación. (1806-1852). Buenos Aires: Editorial Sudamaricana.

GUERRA, François-Xavier (1999/2000). A nação na América espanhola: a questão das origens. Revista Maracanan. Rio de Janeiro, I, (1).

LEITE, Renato Lopes (2000). Republicanos e libertários. Pensadores radicais no Rio de Janeiro (1822). Rio de Janeiro: Civilização Brasileira.

LYRA, Maria de V. (1995). Memória da Independência: marcos e representações simbólicas. Revista Brasileira de História. São Paulo, 15(29): 173-199.

MAGNOLI, Demétrio (2003). O estado em busca do seu território. In: JANCSÓ, István (org). Brasil: formação do Estado e da Nação. São Paulo: Hucitec; Unijuí; FAPESP, pp.285-296.

MATTOS, Ilmar Rohloff de (1987). O tempo Saquarema. São Paulo, HUCITEC/INL.

MOREL, Marco (2005). As transformações dos espaços públicos: imprensa, atores políticos e sociabilidades na cidade imperial. (1820 -1840). São Paulo: Hucitec.

MYERS, Jorge (2007). A Revolução de Independência no Rio da Prata e as origens da nacionalidade argentina. In: PAMPLONA, Marco A. \& MADER, Maria Elisa (org.). Revoluções de independências e nacionalismo nas Américas, Região do Prata e Chile. V.1 São Paulo: Paz e Terra.

NEVES, Lúcia Maria Bastos P. (2003). Corcunda e constitucionais: a cultura política da independência. (1820-1822). Rio de Janeiro: FAPERJ.

(2012). A Vida Política. In: SILVA, Alberto da Costa e (coord.) (2012). Crise colonial e Independência 1808-1830. Rio de Janeiro: Mapfre/Objetiva, pp.95-97. (2009) (org.). Livros e impressos: retratos do setecentos e do oitocentos. Rio de

(1995). O Império Luso-Brasileiro redefinido: o debate político da independência (1820-1822). Revista do instituto histórico e geográfico brasileiro. Rio de Janeiro: 156 (387): pp. 297-307, abr.-jun.

PANTALEÃO, Olga (1993). A presença inglesa. In: HOLANDA, Sérgio Buarque de. História geral da civilização brasileira. Tomo II: o Brasil monárquico: o processo de emancipação. Rio de Janeiro: Ed. Bertrand Brasil, pp.64-99.

PIMENTA, João Paulo (2006). Estado e Nação no Fim dos Impérios Ibéricos no Prata (1808-1828). São Paulo: Hucitec.

ROMERO, Ricardo (2008) (comp.) Mariano Moreno: política y gobierno en su pensamento. Buenos Aires: Ediciones Cooperativas. 
SILVA, Luiz Geraldo (2005). Pernambucanos sois Portugueses! Natureza e modelos políticos das revoluções de 1817 e 1824. Almanack Braziliense. São Paulo. Número 01, maio: pp. 67-79.

SOUZA, J. A. (1993). O Brasil e o Prata até 1828. In: HOLANDA, Sérgio Buarque de. História geral da civilização brasileira. Tomo II: o Brasil monárquico: o processo de emancipação. Rio de Janeiro: Ed. Bertrand Brasil, pp. 300-328.

TERNAVASIO, Marcela (2005). Ser insurgentes frente a la "nación de dos hemisferios" la disputa argumentativa en el Río de la Plata em los años posrevolucionarios. In: NUN, José. Debates de Mayo: nación, cultura y política. Buenos Aires: Celtia-Gedisa: Secretária de Cultura de la Presidência de la Nación, 2005. pp.77-90.

TITTO, Ricardo J. de (2009). El pensamiento de los hombres de Mayo. Buenos Aires: El Ateneo.

VERDO, Geneviève (2008). Soberania do Povo ou dos Povos? A dupla face da soberania durante a Revolução de Independência (Rio da Prata - 1808-1820). Revista de História-USP. São Paulo, pp.37-64.

Artigo recebido em 13 de abril de 2020.

Aprovado em 26 de junho de 2020.

DOI: $10.12957 /$ intellectus.2020.52469 